\title{
Assessment of Economic Losses due to Agricultural Accidents in Selected Districts of Tamil Nadu, India
}

\author{
M. Dinesh Pandi ${ }^{1 *}$ and B. Shridar ${ }^{2}$ \\ ${ }^{1}$ Department of Farm Machinery and Bio-Energy, AEC \& RI, Kumulur, \\ Trichy, Tamil Nadu, India \\ ${ }^{2}$ FMP, AMRC, AEC\&RI, TNAU, Coimbatore, Tamil Nadu, India \\ *Corresponding author
}

\begin{tabular}{|c|c|}
\hline & A B S T R A C T \\
\hline Keywords & \multirow{6}{*}{$\begin{array}{l}\text { The total number of agricultural accidents recorded in the selected districts of Tamil Nadu } \\
\text { for the calendar year } 2012-2013 \text { was } 305 \text {. Out of these } 21 \text { were fatal accidents and the } \\
\text { remaining } 284 \text { were non-fatal accidents. Sources wise Classification of accidents farm } \\
\text { machinery contributed ( } 120 \text { accidents) followed by hand tool (137) and other sources ( } 48 \text { ). } \\
\text { According to the analysis of the age of the agricultural accident victims, majority of the } \\
\text { accident victims were ( } 45.90 \text { per cent) age of above } 45 \text { years. In addition sex group of } \\
\text { accidents victims resulted the highest of male ( } 59.34 \text { percent) followed by female ( } 40.66 \\
\text { per cent). Slashing of sugarcane, paddy and grass accounted for two-third of the accidents } \\
\text { causing cut and hit injuries of moderate severity The estimated economic losses due to } \\
\text { fatal accidents in selected districts were } 1.83 \text { crores and economic losses due to non-fatal } \\
\text { for moderate and serious injury, the medical treatment cost was in the range between } \\
\text { Rs. } 2500 \text { to } 25000 \text { and } 15000 \text { to } 60000 \text { and the work lost was } 18 \text { to } 45 \text { days. }\end{array}$} \\
\hline Agricultural accidents, & \\
\hline Accident prevention, & \\
\hline $\begin{array}{l}\text { Estimation of accident } \\
\text { economic losses. }\end{array}$ & \\
\hline Article Info & \\
\hline $\begin{array}{l}\text { Accepted: } \\
\text { 10 October } 2017 \\
\text { Available Online: } \\
10 \text { December } 2017\end{array}$ & \\
\hline
\end{tabular}

\section{Introduction}

The population engaged in world food production is of great importance. Agriculture employs half of the world labour force and engages 1.3 billion workers in agricultural production worldwide. The proportion of the workforce engaged in agriculture is under 10 per cent in the more developed regions (under 3 per cent in the United States). The proportion is 49 per cent worldwide with almost 60 per cent concentrated in developing countries. The proportion of women and children in agricultural employment is also increasing. Women, now account for 20 to 30 per cent of total agricultural waged employment. Child labour is widespread in agriculture according to International Labour Organization. In number of countries, the rate of economically active children between the ages 5 and 14 may be as much as 30 per cent of the agricultural workforce.

Tamil Nadu has registered a fall in the number of people involved in agricultural activities during 2001-2011 as compared to the previous decade, As per Directorate of Census operations of Tamil Nadu "Out of 32.9 million total workers, 4.25 million are cultivators and another 9.6 million are agricultural labourers. Nearly 42.1 per cent of the workers are engaged in agricultural 
activities compared to 49.3 per cent in census 2000-2001. During the decade 2001-11, the census results show a fall of about $8,70,000$ in cultivators and an increase of about 9, 70,000 in agricultural labourers, According to the 2011 census data, the number of male cultivators decreased to 2.7 million from 3.3 million in census 2001. Among the females, the number of female cultivators has reduced to 1.52 million in census 2011 from 1.85 million in census 2001 .

A worker in agricultural industries of India as well as Tamil Nadu state has received a great deal of attention because of their high risk of fatal injuries and suspected risk for serious non-fatal injuries. A major problem with planning injury prevention programmes for agricultural workers is due to lack of surveillance data, especially for non-fatal and fatal injuries In this situation, this research programme aims to add to the knowledge that is necessary for understanding of risks and safety involved in agriculture. The purpose is to consider accident risks in farming, by defining problem areas of workers risks by means of direct intervention. This is accomplished by collecting data related to agricultural injuries (fatal and non-fatal) that occur during a calendar year on a random sample of villages in the selected districts of Tamil Nadu.

\section{Materials and Methods}

\section{Selection of village}

The objective carried is archived to some of the important operational issues of the investigation viz., sampling technique, development of questionnaire, method of data collection, data processing, in addition to description of the selection of study variables. Attempt has been also made about the identification of key informants to ensure the completion of various activities involved in the survey in a time bound manner. While selecting the blocks and villages from the study area, it was decided to adopt the random sampling technique which has an advantage that each member of the population (blocks and villages) with equal and known chance will be selected. The non-probabilistic sampling technique (Snowball) was also used in this study to identify the respondents (victim) in the selected villages. It was considered because it may be extremely difficult or cost prohibitive to locate respondents (agricultural accident victim). In these situations, considering the advantage of this technique, it can dramatically lower search costs. Snowball sampling relies on referrals from initial subject to generate additional subjects and also used to get a lot of information quickly. This sampling technique also allows the researcher to select several key people (informants) for interview and these may lead on to further important contacts to be interviewed. At the same time, these advantages come at the expense of introducing bias because the technique itself reduces the likelihood, that the sample will represent a good cross section from the population. The key informants for this study were identified as village administrative officer, panchayat presidents, revenue inspectors, agricultural officers, and agricultural extension officials in the selected villages of the district. During the study period, the contacts were established with the informants, which lead to easy access of the victim by the investigator instantly in the selected villages

\section{Definition of terms}

There is no standard definition of agricultural injury (Howell and Smith, 1973; Kumar et al., 2000). AICRP on ESA, Bhopal, India has defined the agricultural accident as an accident occurred while carrying out any agricultural activity with or without hand 
tools, implements and machines on the farm or outside the farm. The injury occurred to the worker is not intentional; rather it is a result of unsafe act or unsafe machine or unsafe environment. The worker may be a paid labourer or family labourer or the farmer himself or herself (Gite, 2005). This definition is recommended for the collection of agricultural accident data in India and hence this definition was used in the present study. Accident occurred while using any hand tool, implement or powered machinery was considered as farm implement-related agricultural accident whereas accident without use of any hand tool, farm implement and machinery was considered as other agricultural (non-farm implement-related) accident. Other agricultural accident may occur due to various reasons like snake bite, noise, vibration, and magnitude of load carrying, falling from height, falling objects and electricity (Nag and Nag, 2004). Furthermore, injury severity descriptions differ widely. Severity of injuries due to agricultural accidents varies from minor injuries, crushing injuries to amputations, and fatalities. In the present study, Abbreviated Injury Scale (AIS) provided by the Association for the Advancement of Automotive Medicine (1990) was used to describe severity of injury. In this scale, injuries are ranked on a scale of 1-6 (1 minor, 2 moderate, 3 serious, 4 severe, 5 critical and 6 unsurvivable injuries). Mohan and Patel (1992), Varghese and Mohan (1991) and Jansson and Jacobsson (1988) have also used AIS.

\section{Collection of data}

For considering the study period of one year (2012-2013) the agricultural accident survey work was carried out in three selected districts of Tamil Nadu from the cluster of thirty two districts. It was decided to select the block randomly in each districts of survey programme. The blocks randomly selected for conducting the survey, which was decided to carry out the survey only in seventy selected sampling villages. Preliminary information of the victim like name, age, address and brief details of the accident was collected during this meeting. Based on this information victims of the accident were identified and personally interviewed and gather the complete information about the accident and its effect. The information provided by the victim was noted in the structured form used for the data collection. The information like present age, experience of working in farm, year and season of accident, type of injury, its severity, approximate cost involved in the treatment of victim, period of hospitalization, days of absence from the work were collected directly from the victim. The personal interview of the accident victim gave the insight into the reliability of the data besides indicating the type of injury, its severity and causes of accident. The photograph of the victim was also collected.

\section{Analysis of data}

Farm implement related and other agricultural (non-farm implement related) accidents were separated. Duration of work before the occurrence of accident and the work activity during the accident were analyzed. All the injuries due to accidents were further categorized into various types of injuries, viz., cut, falls, slip, etc., and the causes for the occurrence of such injuries were identified. The information on the nature of injury and injury sustained body part was analyzed to determine its severity as per AIS. The details of the victim, viz., age, sex and education were analyzed to study the distribution of injuries across various groups. The monetary loss to individual victim due to accident was calculated by adding the expenditures incurred towards the treatment of injury, repair of damaged farm implements during 
accident and income loss due to absence from work. Expenditure towards the treatment of injury was estimated by considering standard charges for various treatments, viz., X-ray, injection, operation, admission charge, etc., in the government supported hospitals while estimating the income loss due to absence from work (Kumar and Dewangan, 2009).

Estimation of Economic losses of agricultural accidents in the selected Villages

Researchers, insurance companies and policy makers have difficulty in placing the value on life or in the case of an accident death, the value of the life that was prematurely lost. In an effort to place the quantitative value on the cost of accidents, injury prevention, specialists have developed a procedure to establish an estimate of years of potential life lost (YOPL). This is estimated by subtracting the age at death from age when the worker would stop productive work. In western countries the age when the worker would stop productive work is 65 years, where 65 is considered as a most frequent retirement age. In India the retirement age is 60 years. Since many farmers /workers continue to work on farm or participate in farm related activities after the age of 60 years, the YOPL used for the present study was based on the productive life of 65 years. To calculate the years of productive life lost, the mean age of accident victim was established from the mean age of victims of accidents in the surveyed villages, which works out to 35 years and the total productive life span was taken as 65 years. Thus the mean value of years of potential life lost would be 30 years. For the estimation of monetary loss, due to fatal accidents, the number of days of employment for agricultural workers can be taken as 290 days per year (GOI, 2013). Considering the minimum wages per day as Rs. 100 (as per Tamil Nadu Government approved wages), the total cost of one life lost would be about 8.7 lakhs.

\section{Results and Discussion}

Table 1 also indicates that 181 (59.34\%) victims were men, while 124 (40.66\%) were female. Kumar et al., (2009) reported that among the victims of agricultural accidents in north eastern region of India, 73 (46.2\%) victims were women, while $85(53.8 \%)$ were men. Naturally, agricultural tasks required higher energy requirements for long time and could met only by majority of male workers while women are involved in operations like transplanting and weeding which does not involve any tools or implements or machines.

However, in the agricultural, women participate in almost all the agricultural operation including harvesting of paddy and weeding, which involves the use of hand tools (Saikia and Das, 2004). The details of sex wise classification of accident victims are furnished in Table 2. Majority of the accident victims ( 45.90 per cent) were belonged to the age group of above forty five.

\section{Type of event and injury}

From Figure 1 it is found that a maximum of 27.21 per cent of accidents were reported as hit by fingers due to hand tools when harvesting the paddy crops and sugarcane stems. It was followed by cut injury (18.69 per cent) and was reported due to operation of crusher with improper design of the feed chute and lack of cover around rotating parts as shown in Figure 1 noticed and other type of injury which caused 17.05 per cent due to ignorance of operators and lack of safety device for sprayers followed by Crush injury reported as 7.21 per cent that is body parts caught in between moving machinery parts such as rollers in crushers (Plate 4.15). Threshing drum in threshers and fall type 
accident were reported as 5.57 per cent followed by over turning 1.64 per cent and snake bite 11.5 per cent.

\section{Abbreviated Injury Scale (AIS)}

The accidents were classified based on Abbreviated Injury Scale standardized by Association for the Advancement of Automotive Medicine (1990) which was used to describe severity of injury. Agricultural injuries vary in intensity from minor injuries, crushing injuries to amputations and fatalities. The severity of injuries may vary with the type of machine involved. Injury severity descriptions also differ widely. ISS (Injury Severity Score) has been used by McElfresh and Bryan (1973). Similarly, in the case study on agriculture accident injuries classified based on the AIS (Abbreviated Injuries Scale) has been used by Mohan and Patel (1992). Figure 3 showed that a total of $49 \%$ accidents were reported as moderate injuries (AIS2). This was due to hand tools and sugarcane crusher. About 24\% injuries were drawn under minor injuries, due to sprayer, sickle, snake bite (AIS1). Whereas severe injury happened was $9 \%$ and $10 \%$ was serious injury which necessitated major hospitalization for fracture in arms and legs and amputation of fingers in few cases were observed in this category of accidents. These injuries occurred due to sugarcane crusher, power tiller and tractor. Critical and unsurvivable injury was $1 \%$ (AIS5) and 7\% (AIS6) injuries were due to power tiller, tractor and snake bite (Fig. 2).

Table.1 Frequency and percentage distribution for sex group of accident victims

\begin{tabular}{|c|c|c|c|c|c|c|}
\hline Sl.No & Sex & Coimbatore & Theni & Thanjavur & Frequency & Percentage \\
\hline 1 & Male & 18 & 57 & 106 & 181 & 59.34 \\
\hline 2 & Female & 24 & 35 & 65 & 124 & 40.66 \\
\hline \multicolumn{2}{|c|}{ Total } & 42 & 92 & 171 & 305 & 100.00 \\
\hline
\end{tabular}

Table.2 Details of different age group of accident victims

\begin{tabular}{|c|c|c|c|c|c|c|}
\hline SI. No & Age & Coimbatore & Theni & Thanjavur & Frequency & Percentage \\
\hline 1 & $<15$ & 1 & 0 & 2 & 3 & 0.98 \\
\hline 2 & $15-29$ & 5 & 9 & 16 & 30 & 9.84 \\
\hline 3 & $30-45$ & 11 & 48 & 73 & 132 & 43.28 \\
\hline 4 & $>45$ & 25 & 35 & 80 & 140 & 45.90 \\
\hline \multicolumn{2}{|c|}{ Total } & 42 & 92 & 171 & 305 & 100.00 \\
\hline
\end{tabular}

Table.3 Calculation of economic losses due to agricultural accidents

\begin{tabular}{|l|c|c|c|c|c|c|}
\hline SI.No & $\begin{array}{c}\text { AIS } \\
\text { injury } \\
\text { scale }\end{array}$ & $\begin{array}{c}\text { No. of } \\
\text { accidents }\end{array}$ & $\begin{array}{c}\text { Absence from } \\
\text { work due to } \\
\text { injuries in the } \\
\text { range (No. In days) }\end{array}$ & $\begin{array}{c}\text { Approximate } \\
\text { expenditure in } \\
\text { medical treatment } \\
\text { (Amount) }\end{array}$ & $\begin{array}{c}\text { Total Income loss due } \\
\text { to absence from work } \\
\text { (No. of days absence } \times \\
\text { per day earning }\end{array}$ & $\begin{array}{c}\text { Total loss due to accidents } \\
\text { in terms of cost (Treatment } \\
\text { cost down time cost + } \\
\text { machinery repairing cost }\end{array}$ \\
\hline 1 & Minor & 74 & $2-4$ & 0 & $(2-4) \times 100=200-400$ & $(200-400)$ \\
\hline 2 & Moderate & 149 & $18-45$ & $2500-25000$ & $\begin{array}{c}(18-45) \times 100 \\
=1800-4500\end{array}$ \\
\hline 3 & Serious & 30 & $30-120$ & $15000-60000$ & $\begin{array}{r}(30-120) \times 100 \\
=3000-12000\end{array}$ \\
\hline 4 & Severe & 28 & $35-360$ & $25000-200000$ & $\begin{array}{c}(35-360) \times 100 \\
=3500-36000\end{array}$ \\
\hline 5 & Critical & 3 & $120-360$ & $32000-200000$ & $\begin{array}{c}(120-360) \times 100 \\
=12000-36000\end{array}$ & 28500 \\
\hline
\end{tabular}


Fig.1 Type of event and injury

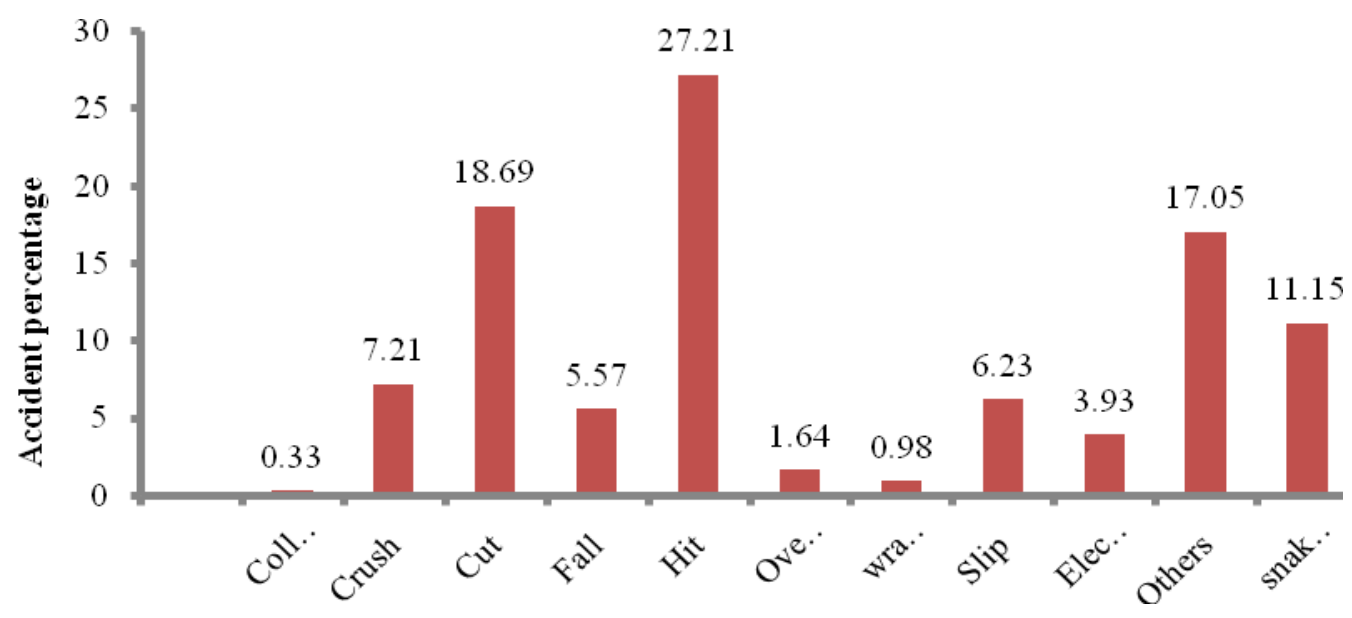

Fig.2 Different cut and hit injuries photograph

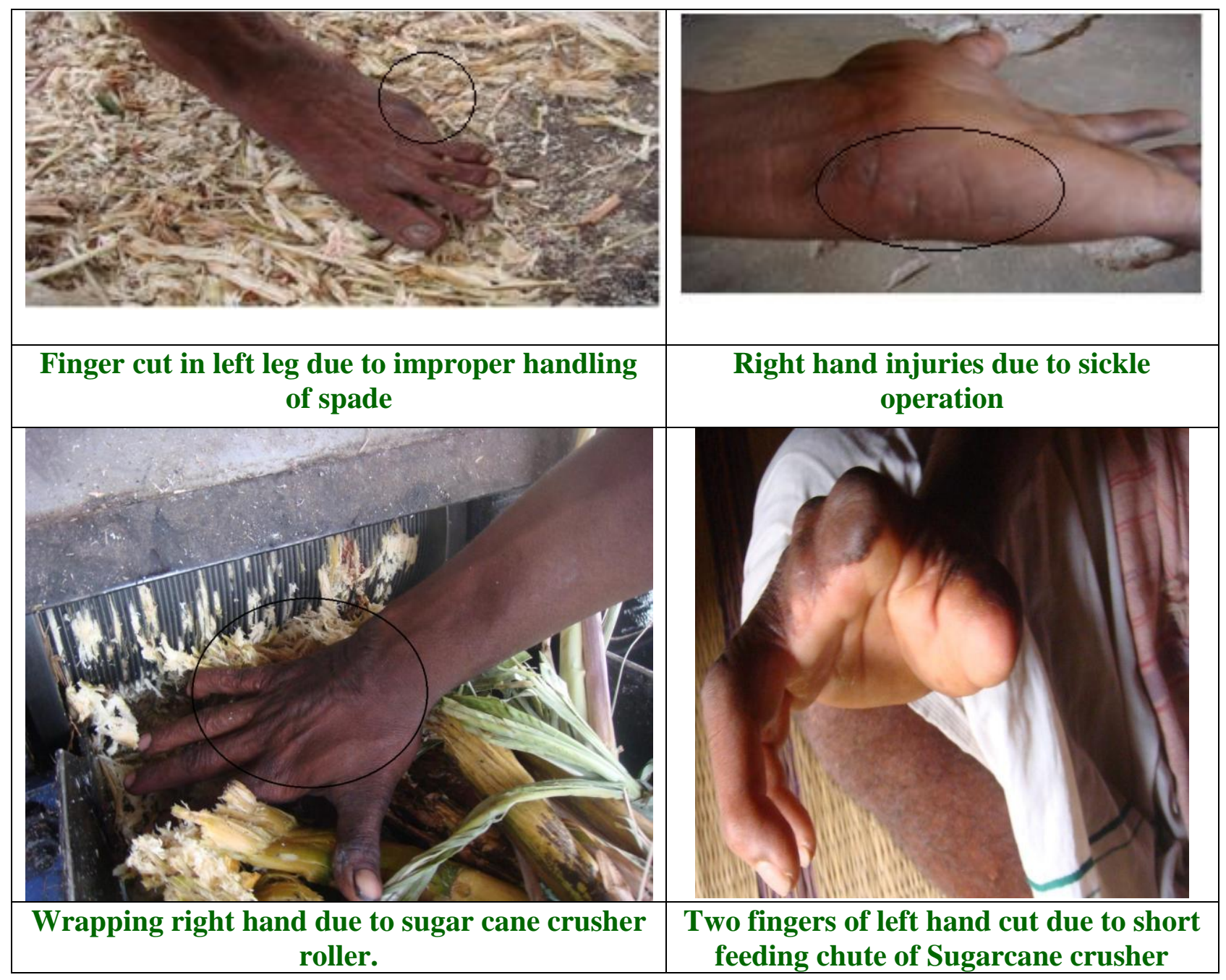


Fig.3 Severity of injury in abbreviated injury scale
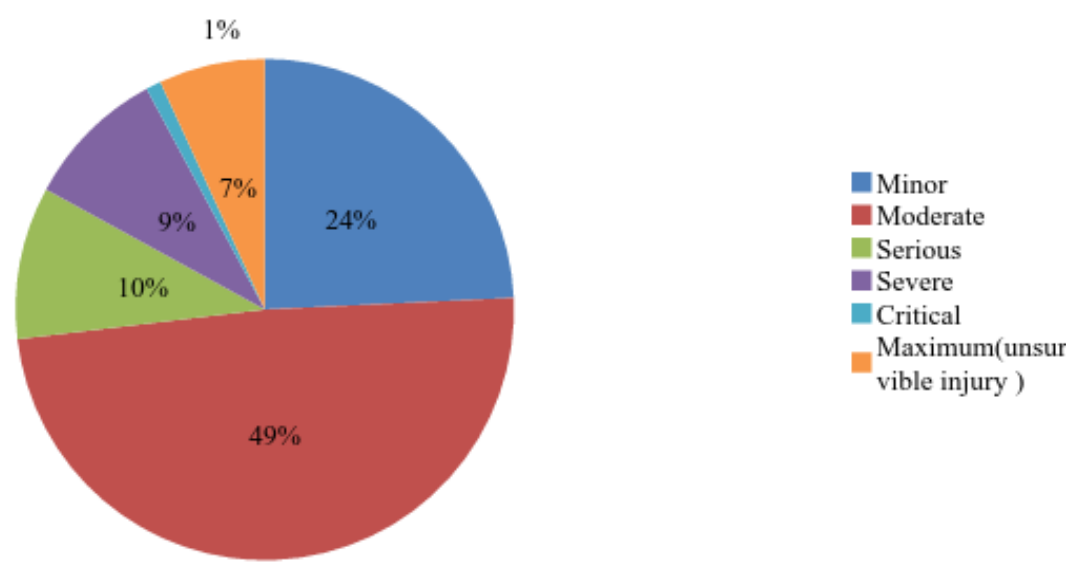

Estimation of economic losses due to fatal to 60000 and the work lost were 18 to 45 accidents days, in moderate injury it was 30 to 120 days. In case of serious injury the cost for Monetary loss per year in selected district due to Accident deaths (fatal) $=21 \times$ Rs.8.7 lakhs $($ total cost of remaining life $)=21 \times 870000=$ 1.83 crores

\section{Estimation of economic losses due to non- fatal accidents}

Agricultural accidents of 305 were surveyed out of this the account of 284 non-fatal accidents were selected and economic losses were estimated under the category of minor74, moderate-149, serious- 30, severe -28 , crtical-3.These injury sustained during the agricultural operation with tractor, power tiller, thresher, sugarcane crusher and hand tools in the farmer and agricultural labours based on the injury severity the cost for medical treatment and absence for work varied. Absence from work due to injury in number of days and approximate expenditure in medical treatment cost in amount was high. These two were varied based on the severity of injury in minor, moderate, serious, severe and critical injuries. In moderate and serious injury the medical treatment cost were in the range between Rs.2500 to 25000 and 15000 and the work lost were 35 to 360 days and critical injury medical treatment cost were Rs 32000 to 2 lakhs and the work lost 120 to 360 days. In case of minor injury, treatments were taken from the government hospitalization and did not require professional treatment and the work lost were less than 4 days. Considering the agricultural workers minimum wages per day (Rs: 100 as per GOI).the losses was calculated (Table 3 ).

\section{Agricultural accident prevention or minimization measures}

By analysing the survey data, it was found that minor problems occurred in more and in few cases occurrence of serious problems like cancer due to pesticide poisoning while operating sprayer without safety devices to face and nose. Most of the rural people used to operate the manual sprayer without mask. So to eliminate these problems, creating awareness among farmers, hand tool injuries are occurred due to poor quality and improper design. For manual harvesting of paddy and sugarcane, it is necessary to provide the hand 
gloves with grip for the sickles. With respect to ergonomic aspects, it is necessary to improve the design of spade and sickle for operators comfort and continuous working without rest

The total number of agricultural accidents recorded in selected districts for the calendar year 2011-2013 was 305. Out of these, 21 were fatal accidents and the remaining 284 were non-fatal accidents. Sources wise classification of accidents farm machinery contributed 120 accidents followed by hand tool 137 and other sources (48).

As per AIS (Abbreviated injury scale) classification, $48.85 \%$ of accidents ranked as "Moderate (AIS scale 2), Minor 24.26 \% (AIS 1) followed by serious $9.84 \%$ (AIS 3) and $9.18 \%$ severe (AIS 4 ) of the total percentage of injury scale.

The estimated economic loss due to fatal accidents in selected districts was 1.83 crores.

Calculated economic losses due to non-fatal in the moderate and serious injury, the medical treatment cost was in the range between Rs.2500 and 25000 and 15000 to 60000 and the work lost was 18 to 45 days, In moderate injury it was 30 to 120 days.

\section{References}

Gite, L.P., 2005. Project coordinator's report. In: Proceedings of 3rd Workshop of All India Coordinated Research Project on Ergonomics and Safety in Agriculture, CIAE, Bhopal, India, pp. 3-17.
Howell, J.M., Smith, E.S.O., 1973. An agricultural accident survey in Alberta, 1970. Canadian Journal of Public Health/Revue Canadienne de Sante'e Publique, pp.36-43.

Jansson, B.R., Jacobsson, B.S., 1988. Medical consequences of work-related accidents on 2454 Swedish farms. Scandinavian journal of work, environment \& health, pp.21-26.

Kumar, A., Varghese, M., Mohan, D., 2000. Equipment-related injuries in agriculture: An international perspective. Injury control and safety promotion, 7(3), pp.175-186.

Kumar, G. P., Dewangan, K. N. (2009). Agricultural accidents in north eastern region of India. Safety science, 47(2), 199-205.

McElfresh, E.C., Bryan, R.S., 1973. Power takes -off injuries. The Journal of Trauma 13, 775-782.

Mohan, D., Patel, R., 1992. Design of safer agricultural equipment: Application of ergonomics and epidemiology. International Journal of Industrial Ergonomics, 10(4), pp.301309.

Nag P.K., Nag, A., 2004. Drudgery, accidents and injuries in Indian agriculture. Industrial Health, 42(2), pp.149-162.

Varghese, M., Mohan, D., 1991. Transportation injuries in rural Haryana, North India. In: Proceedings of the International Conference on Traffic Safety, New Delhi, India, pp. 326329.Verma, S.R., Rawal, G.S., Bhatia.

\section{How to cite this article:}

Dinesh Pandi M. and Shridar B. 2017. Assessment of Economic Losses due to Agricultural Accidents in Selected Districts of Tamil Nadu, India. Int.J.Curr.Microbiol.App.Sci. 6(12): 1132-1139. doi: https://doi.org/10.20546/ijcmas.2017.612.127 